\title{
A estrutura composicional dos textos de estudantes sobre ciclos de materiais: evidências de uso e apropriação da linguagem científica
}

\author{
The compositional structure of student texts \\ on material cycles: evidence of use and appropriation \\ of scientific language
}

Nilma Soares da Silva ${ }^{1}$ • Orlando Gomes de Aguiar Junior ${ }^{1}$

\begin{abstract}
Resumo: Neste trabalho, apresentamos uma análise das respostas de estudantes do $8^{\circ}$ ano do Ensino Fundamental a uma questão de pós-teste aplicado depois de concluída uma sequência de ensino sobre reações químicas. O foco da análise consiste em identificar os modos de uso e apropriação da linguagem científica pelos estudantes. Utilizamos elementos da gramática funcional de Halliday e Martin para examinarmos a estrutura composicional dos textos. Tal análise foi feita considerando o processo de formação e evolução de conceitos a partir do referencial sociocultural de Vigotsky, destacando-se evidências de apropriação dos conceitos de transformação, elementos e substâncias químicas. Os resultados indicam uma variedade de estilos composicionais, prevalecendo a explicação narrativa mais próxima da linguagem cotidiana. Concluímos que o processo de apropriação é longo e que o pensamento dos estudantes, apesar de ter traços de coerência e objetividade, difere do pensamento conceitual.
\end{abstract}

Palavras-chave: Ensino de química. Ensino Fundamental. Linguagem científica. Formação de conceitos.

\begin{abstract}
In this paper we present an analysis of the responses of 8th grade students (13-14 years old) to a questionnaire post-test administered after a learning sequence about chemical reactions. The focus of the analysis is to identify ways of using and the appropriation of scientific language by the students. We use elements of functional grammar of Halliday and Martin to examine the compositional structure of texts. Such an analysis was made considering studies of the formation and evolution of concepts from Vigotsky's sociocultural approach, highlighting evidence of appropiation of the concepts of transformation, chemical elements and substances. The results indicate a variety of compositional styles, and a prevailing narrative explanation closer to everyday language. We conclude that the appropriation process is long and the thinking of students, despite having traces of consistency and objectivity, differs from conceptual thinking.
\end{abstract}

Keywords: Chemistry teaching. Middle school. Scientific writing. Conceptual learning.

\footnotetext{
${ }^{1}$ Departamento de Métodos e Técnicas de Ensino, Faculdade de Educação, Universidade Federal de Minas Gerais (UFMG), Avenida Antônio Carlos, 6627, Campus Pampulha, CEP 31270-90, Belo Horizonte, MG, Brasil. E-mail: <nilmasoares@yahoo.com.br>
} 


\section{Introdução}

Este estudo se realiza na perspectiva de uma educação que considera que a aprendizagem em ciências se realiza por meio da apropriação das linguagens que moldam e configuram os modos de pensar das ciências. Tal perspectiva considera, de um lado, a importância da linguagem e das mediações simbólicas no desenvolvimento e formação de conceitos, e, de outro, a relação entre modos de falar e formas de pensar e estabelecer relações com o mundo e as coisas (MORTIMER, 2000; VIGOTSKI, 2001; WERTSCH, 1991, 1998).

Numa perspectiva histórico-cultural do desenvolvimento humano, consideramos o processo de conceitualização como uma prática social mediada pela palavra e pelo outro (FONTANA, 2000). Caracterizamos esta pesquisa no campo de estudos de formação de conceitos, que considera as condições funcionais de surgimento do conceito. Nesse contexto, o conceito é constituinte de um processo vivo e complexo de pensamento, exercendo sempre alguma função de comunicar, assimilar, entender e resolver um problema. Adotamos, como referencial teórico, as ideias defendidas por Vigotsky (2001, 2003), e autores contemporâneos que se apoiam nele, para compreender a formação de conceitos científicos em salas de aula de ciência (LIMA; AGUIAR JR.; DE CARO, 2011; MORTIMER; SCOTT, 2003; WELLS, 2008).

Assumimos, ainda, que aprender ciências envolve a aprendizagem, em contextos relevantes, das linguagens da ciência (LEMKE, 1990; SUTTON, 1992), ou, melhor dizendo, da linguagem social da ciência escolar (BAKHTIN, 2003; MORTIMER; SCOTT, 2003). Parecenos, portanto, fundamental examinar os modos pelos quais os estudantes vão se apropriando progressivamente dos modos de dizer da ciência, que traduzem novas formas de pensar o mundo. Para tal, nos valemos da caracterização, feita por Halliday e Martin (1993), do texto científico e do texto didático-científico.

O trabalho faz parte de uma tese de doutorado (SILVA, 2009) que teve por objeto os modos de uso e o processo de apropriação do conceito de elemento químico por estudantes do $8^{\circ}$ ano do Ensino Fundamental, em estudo sobre as transformações dos materiais. O interesse pelo conceito de elemento químico decorre, de um lado, da constatação da dificuldade que os estudantes apresentam em lidar com esse conceito fundamental, bem como das implicações trazidas para o desenvolvimento de ideias posteriores, mais complexas. O conceito de elemento químico e a distinção entre elemento e substância são fundamentais, por exemplo, para o desenvolvimento do modelo de reações químicas. Esse conceito também inaugura um modo químico de falar e pensar sobre a constituição dos materiais. Por outro lado, o uso indiscriminado do termo elemento químico, pelos estudantes do Ensino Médio, tem mostrado que a compreensão deles sobre as substâncias e os materiais não tem se desenvolvido de maneira adequada na Educação Básica.

A pesquisa foi realizada em uma escola da rede particular de ensino, e na sala de aula de um professor que constrói um ambiente de aprendizagem que favorece as discussões e participação dos estudantes em inúmeras atividades.

No recorte aqui apresentado, analisamos as respostas dos estudantes a uma questão de pós-teste, após o desenvolvimento de uma sequência de ensino. A análise que fizemos do texto foi orientada pelas seguintes questões de pesquisa: (1) os textos produzidos mostram o domínio de conceitos científicos de elemento químico e dos ciclos de materiais na natureza? (2) os textos produzidos trazem marcas do discurso científico e, assim, sinalizam sua apropriação? 


\section{Referencial teórico}

Para identificar o grau de uso e apropriação da linguagem científica pelos estudantes, examinamos alguns critérios, inspirados em análise semelhante feita por Mortimer, Vieira e Araújo (2010), baseados em elementos da gramática funcional de Halliday e Martin (1993). Fizemos uma adequação dos critérios utilizados por esses autores à natureza da tarefa proposta na questão. Ao final, utilizamos os seguintes critérios, comentados a seguir:

- Presença de nominalizações e metáforas gramaticais;

- Uso de verbos de relações;

- Uso dos termos elemento, substância e transformação;

- Uso de referentes empíricos (diretamente observáveis);

- Uso de referentes teóricos (não diretamente observáveis);

- Relação entre referentes empíricos e teóricos;

- Tipo de linguagem (científica ou cotidiana);

- Tipo de sequência textual predominante (narrativa, descritiva, explicativa ou argumentativa).

Uma das principais características do texto científico (e, também, do texto científico escolar) é a presença de processos nominalizados, o que lhe confere grande densidade léxica. Segundo Halliday e Martin (1993), no contexto da produção e comunicação do conhecimento científico, a nominalização permite, ainda, estabelecer relações entre processos por meio de verbos ou expressões verbais. Nos textos que iremos examinar, parte desses processos nominalizados está apresentada na Figura 1, que serve de pretexto ao texto a ser produzido. Assim, não é de admirar que todos os 18 textos produzidos usem nominalizações como: fotossíntese, respiração e combustão. Algumas dessas nominalizações resultam em metáforas gramaticais, mas nem todas elas.

Podemos exemplificar a presença ou ausência de metáforas gramaticais nos exemplos seguintes:

Sentença 1: "Por meio da respiração, os seres vivos liberam gás carbônico para a atmosfera".

Sentença 2: "A respiração dos seres vivos libera gás carbônico para a atmosfera".

No primeiro caso, o sujeito da ação são os seres vivos, o agente que, por meio de um processo nominalizado (e de alta densidade léxica), libera $\mathrm{CO}_{2}$ para a atmosfera. No segundo caso, o processo nominalizado (e abstrato) toma o lugar do sujeito da ação. Temos, então, uma metáfora gramatical, ou seja, a substituição de uma classe gramatical por outra.

As metáforas gramaticais ocorrem, ainda, quando os verbos expressam relações. e não ações concretas dos sujeitos. Assim, o verbo 'libera'. na sentença 2. relaciona a respiração, o gás carbônico e a atmosfera. Por essa razão, procuramos identificar, nos textos produzidos pelos estudantes, o tipo de verbo utilizado e a função que cumprem nos enunciados.

Para examinarmos os tipos de sequência textual predominante, caracterizamos a presença da narrativa, da descrição, da explicação ou da argumentação. Para Bronckart (1999), as sequências narrativas apresentam ações sucessivas de protagonistas, marcadas temporalmente, e que conduzem a uma tensão e a um clímax. Já as sequências descritivas são identificadas em textos que envolvem enunciados que se referem a um sistema, um objeto ou um fenômeno em termos de seus constituintes, suas propriedades ou dos deslocamentos espaço-temporais 
desses constituintes. Ainda em Bronckart (1999), destacam-se as sequências explicativas como utilizadas para tratar de um aspecto que se considera problemático. Em Mortimer e Scott (2003), a explicação recorre a algum tipo de mecanismo ou de modelo teórico para se referir a um sistema, objeto ou fenômeno. Finalmente, as sequências argumentativas apresentam enunciados que tratam de aspectos considerados controversos ou com algum grau de incerteza, e que pretendem convencer o interlocutor da validade de um ponto de vista em contraposição a outros.

Não encontramos, nas respostas dos estudantes à questão apresentada, sequências narrativas no sentido proposto por Bronckart, mas explicações que se assemelham a narrativas de acontecimentos como em uma 'estória', conforme sugerem Ogborn et al. (1996). Desse modo, as denominamos 'explicações narrativizadas'. Alguns dos protagonistas dessa 'estória' são tomados da experiência cotidiana (plantas, animais, combustíveis, ar), e são agentes de ações específicas (comem, morrem, são queimados, utilizados, passam de um lugar a outro etc.). Outros protagonistas remetem a termos teóricos (gás carbônico, carbono, fotossíntese, combustão etc.), conectados por verbos de relação (liberam, absorvem, se decompõem, se transformam etc.).

Além de caracterizarmos o tipo de sequência predominante no texto, procuramos identificar, ainda, o tipo de linguagem, se científica, ou cotidiana. Os critérios que usamos para definir se o texto do estudante se aproxima da linguagem científica foram: o uso de entidades abstratas (gás carbônico, carbono, moléculas etc.), a evocação de processos (fotossíntese, respiração, combustão, entre outros), o encadeamento conceitualmente correto entre tais processos, e o uso dos verbos para estabelecer relações entre processos ou para descrever atributos das entidades evocadas no discurso. Ao contrário, os textos foram classificados como mais próximos da linguagem cotidiana quando: evocam referentes empíricos, não fazem distinções entre referentes empíricos e abstratos, não articulam bem os elementos que deveriam compor a explicação, e utilizam verbos para designar ações concretas.

Com esses critérios, pretendemos identificar o grau de uso e apropriação da linguagem científica pelos estudantes.

\section{Metodologia}

O pós-teste foi aplicado, durante uma aula de 50 minutos, a 18 estudantes, sete meses depois de concluída uma sequência de ensino composta por dois capítulos do texto didático adotado': "Os Minerais e a Vida" e "Compreendendo as reações químicas". Cada estudante respondeu individualmente ao pós-teste após explicações dadas pelo professor e pesquisadora sobre os objetivos da atividade, que fez parte da pesquisa desenvolvida que contemplou filmagens realizadas durante três meses de acompanhamento das aulas de Ciências da turma. A sequência de ensino envolveu 36 aulas de 50 minutos e um conjunto de textos e atividades que tinham por objetivo forjar contextos relevantes para o trabalho com conceitos químicos elementares e, assim, introduzir o modelo científico de reação química.

${ }^{2}$ Construindo consciências. São Paulo: Scipione, 2003. v. 3 (os autores deste trabalho são coautores da coleção didática). 
Na questão do teste que apresentamos a seguir, selecionamos alguns aspectos estruturais do texto, de modo a reconhecer a apropriação, por parte dos estudantes, da linguagem social da ciência escolar. Examinamos, além disso, o conteúdo do texto, identificando a quantidade e possível origem dos erros conceituais eventualmente cometidos pelos estudantes.

Figura 1. Questão 1 do pós-teste

Questão 1 - Observe a figura que representa o ciclo do carbono na natureza. Redija um pequeno texto para explicar esse ciclo.

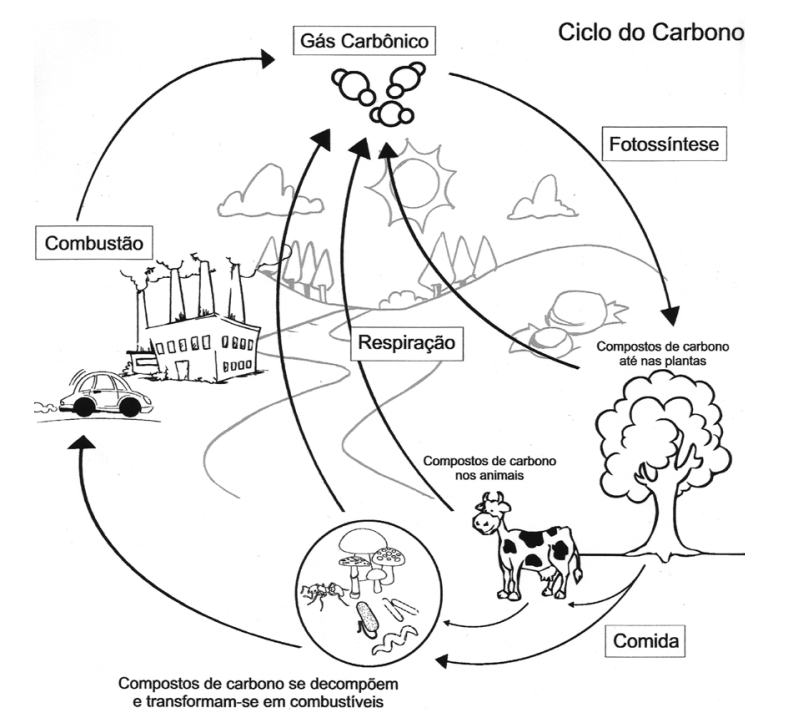

Fonte: Adaptada de: <https://sites.google.com/site/ caseoliveiraambientalista/ecologia-geral/ciclo-do-carbono>. Acesso em: 09 set. 2014.

Com esta questão, pretendíamos oferecer um contexto significativo que demandasse a noção de ciclo de materiais, transformações químicas e a distinção entre elemento químico e substância. No enunciado, a solicitação feita era a de um texto explicativo, referente aos processos indicados no diagrama, relativos ao ciclo do carbono. O diagrama continha vários nomes ou sintagmas nominais. Alguns desses indicando processos (ciclo do carbono, fotossíntese, respiração, combustão, entre outros), e outros indicando classes de referentes, relativos a elementos observáveis (plantas, animais, comida, fábricas, cidades) e não diretamente observáveis (carbono, gás carbônico, compostos de carbono etc.). Vários desses elementos encontram-se nomeados na legenda interna da figura e, por essa razão, a tarefa proposta consistia em compor um texto coordenando os aspectos evocados, de modo a explicar o ciclo do carbono.

O diagrama apresenta dificuldades conceituais de várias ordens: indica, simultaneamente, vários processos interdependentes que ocorrem em diferentes escalas de tempo e espaço; sobrepõe entidades empíricas e outras teóricas cujas relações não são evidentes e contêm altíssima densidade léxica. Apesar disso, esperávamos textos um pouco mais articulados e consistentes do que aqueles que foram, efetivamente, produzidos por boa parte dos estudantes. 
Cabe ressaltar que, na sequência de ensino desenvolvida nas aulas de ciências, os estudantes examinaram diagramas semelhantes, relativos aos ciclos do fósforo e do cálcio, e, também, realizaram estudos sobre o ciclo do carbono.

\section{Resultados e análise}

Procuramos identificar e quantificar, nas respostas dos estudantes, o uso de referentes empíricos, referentes teóricos, grupos nominais e verbos de relação, por sua importância como indicadores do grau de proximidade com o texto científico. Os textos produzidos variaram, em extensão, entre 14 e 87 palavras, com média de 48 palavras por texto.

A presença dos termos elemento, substância e transformação é representativa da aprendizagem dos estudantes, já que a sequência didática utilizada nesta pesquisa envolve o estudo desses conceitos. Entretanto, como mostra a Tabela 1, o contexto da pergunta não evocou a necessidade de usar tais conceitos, embora seja possível reconhecer, nas respostas, o sentido a eles atribuído pelos estudantes.

Tabela 1. Frequência de uso de termos ou expressões nas respostas à questão 1

\begin{tabular}{|c|c|c|c|c|}
\hline Termo ou expressão & $\begin{array}{c}\text { Processo } \\
\text { nominalizado (PN), } \\
\text { referente empírico } \\
\text { (RE), referente } \\
\text { teórico (RT), verbo } \\
\text { de relação (VR) }\end{array}$ & $\begin{array}{c}\text { Aparece no } \\
\text { enunciado ou na } \\
\text { legenda interna } \\
\text { do diagrama? } \\
\text { (número de } \\
\text { ocorrências) }\end{array}$ & $\begin{array}{l}\text { Frequência de uso } \\
\text { (número de textos } \\
\text { em que é usado, } \\
\text { num total de } 18 \\
\text { textos) }\end{array}$ & $\begin{array}{l}\text { Frequência } \\
\text { total (número } \\
\text { de vezes } \\
\text { que é usado } \\
\text { em todos os } \\
\text { textos) }\end{array}$ \\
\hline Ciclo & PN & $\operatorname{Sim}(3)$ & 6 & 8 \\
\hline Ciclo do carbono & PN & $\operatorname{Sim}(2)$ & 1 (incluída em ciclo) & 1 \\
\hline Gás carbônico / CO2 & $\mathrm{RT}$ & $\operatorname{Sim}(1)$ & 13 & $22(14 / 8)$ \\
\hline Oxigênio / O2 & RT & Não & 3 & $3(1 / 2)$ \\
\hline Fotossíntese & PN & $\operatorname{Sim}(1)$ & 12 & 13 \\
\hline Respiração & PN & $\operatorname{Sim}(2)$ & 8 & 13 \\
\hline Decomposição / fermentação & PN & Não & 0 & 0 \\
\hline Transformação & PN & Não & 0 & 0 \\
\hline Combustão & PN & $\operatorname{Sim}(1)$ & 15 & 16 \\
\hline Decompõem / se decompõem & VR & $\operatorname{Sim}(1)$ & 5 & $10(5 / 5)$ \\
\hline $\begin{array}{l}\text { Transformam / transformam-se / são } \\
\text { transformados }\end{array}$ & VR & $\operatorname{Sim}(1)$ & 5 & $5(2 / 2 / 1)$ \\
\hline Combustíveis & RE & $\operatorname{Sim}(1)$ & 6 & 6 \\
\hline Compostos de carbono & $\mathrm{RT}$ & $\operatorname{Sim}(3)$ & 6 & 6 \\
\hline Átomos de carbono & RT & Não & 1 & 1 \\
\hline Moléculas de carbono & $\mathrm{RT}$ & Não & 1 & 1 \\
\hline Carbono & RT & Não & $6^{3}$ & 11 \\
\hline Elemento & RT & Não & 0 & 0 \\
\hline Substância & RT & Não & 0 & 0 \\
\hline Plantas & RE & Sim & 13 & 14 \\
\hline Animais & RE & Sim & 11 & 14 \\
\hline $\mathrm{Ar} /$ atmosfera & $\mathrm{RE}$ & Não & 8 & $14(6 / 8)$ \\
\hline Automóveis / Fábricas / cidades & RE & Não (figura) & 2 & $3(1 / 1 / 1)$ \\
\hline
\end{tabular}

Fonte: Elaborada pelos autores.

\footnotetext{
${ }^{3}$ Além de ciclo do carbono e compostos de carbono.
} 
A análise de frequência total de uso dos termos nas respostas dos estudantes ( $5^{\mathrm{a}}$ coluna da tabela, em que contamos a presença dos termos no total dos 18 textos) indica que os referentes empíricos tiveram preferência nos enunciados dos estudantes: os cinco referentes empíricos (RE) foram utilizados quarenta vezes (média de oito por referente), enquanto os 10 referentes teóricos (RT) foram utilizados apenas 24 vezes (média de 2,4 por referente) e os oito processos nominalizados (PN) estiveram presentes quarenta vezes (média de cinco por processo citado). Entre os termos mais evocados nas respostas dos estudantes - combustão (15), gás carbônico (13), plantas (13), fotossíntese (12), animais (11) -, apenas dois deles não são diretamente ligados à percepção e à experiência cotidiana, e quase todos são muito citados na abordagem que se faz sobre efeito estufa na mídia e nos textos didáticos.

Ficamos relativamente surpresos com a ausência dos termos "elemento", "substância" e "transformação" nas respostas dos estudantes, o que revela que esses conceitos não são ainda familiares a ponto de serem evocados espontaneamente pelos estudantes em situações-problema. O que mais se aproxima de apropriação da ideia de elemento químico é a frequência relativamente alta do termo "carbono" nas explicações dadas (13 respostas contêm expressões como 'compostos de carbono', 'ciclo de carbono', 'carbono dos alimentos' e outras). Apesar disso, como veremos na análise qualitativa, notamos um alto grau de indiferenciação entre os conceitos de elemento e substância nas respostas dadas.

Se considerarmos os critérios apontados por Bronckart (1999), veremos que a maior parte dos textos dos estudantes compõe sequências explicativas, seguindo o que foi solicitado no enunciado da questão (explicar o ciclo do carbono representado na figura). De fato, os estudantes parecem indicar mecanismos que esclareçam aspectos de um conceito tomado como potencialmente problemático.

Identificamos, entretanto, em alguns desses textos, sequências explicativas narrativizadas. Não se trata de uma narrativa clássica, geralmente apresentada com verbos no passado, descrevendo ações de personagens frente a situações complicadoras e que conduzem a um desfecho (BRONCKART, 1999). Apesar disso, vários desses textos contêm elementos de narrativa, quais sejam, articulação dos acontecimentos, geralmente em ordem cronológica, apresentando início, meio e fim, relacionados a um tema. De acordo com Ogborn et al. (1996), a narrativa pode servir a inúmeros propósitos: para explicar, exemplificar ou, simplesmente, narrar algo memorável. No caso dos textos dos estudantes em resposta à questão 1, boa parte deles utiliza elementos de narrativas para explicar um processo (o ciclo do carbono).

Em contraste com as explicações narrativizadas, outras explicações utilizadas pelos estudantes foram caracterizadas como "demonstrativas", posto que pretendem apresentar ou demonstrar os passos ou etapas de uma explicação científica - no caso, do ciclo do carbono.

Em outros casos, os estudantes utilizam os constituintes da figura apresentada na questão e estabelecem descrições dos acontecimentos baseando-se em pares de referentes (plantas/ animais - compostos de carbono/ indústrias) ou, de modo mais completo, considerando todo o ciclo representado na figura. Muitas vezes, como apresentaremos a seguir, os estudantes não conseguem estabelecer relações entre os constituintes e descrevem apenas a figura, sem incorporar, em suas respostas, os conceitos demandados para a explicação do ciclo.

Como veremos, todos os textos produzidos pelos estudantes em resposta à questão 1 do pós-teste, utilizaram o tempo presente. Isso nos parece natural dada a natureza abstrata do problema proposto, que não contém vínculos imediatos com experiências diretas e pessoais dos estudantes. 
O Quadro 1 apresenta dados referentes à análise do aspecto tipo de linguagem nas respostas dos 18 estudantes à questão 1 do pós-teste.

Quadro 1. Tipo de linguagem nas respostas dos estudantes à questão 1 do pós-teste

\begin{tabular}{|l|l|c|c|c|}
\hline \multirow{2}{*}{$\begin{array}{c}\text { Tipo de linguagem } \\
\text { (nº de estudantes) }\end{array}$} & Científica: 3 & Explicação narrativizada & Descrição & Explicação demonstrativa \\
\cline { 2 - 5 } & Cotidiana: 15 & Explicação narrativizada & Descrição & Explicação demonstrativa \\
\cline { 3 - 5 } & & 10 & 5 & 0 \\
\hline
\end{tabular}

Fonte: Elaborado pelos autores.

Sobre o tipo de linguagem, a maioria dos estudantes utiliza a explicação narrativizada em suas respostas. Pelo fato de a questão apresentar uma figura referente ao ciclo do carbono, alguns estudantes utilizaram a linguagem descritiva, valendo-se dos elementos nomeados e representados na figura. $\mathrm{O}$ texto explicativo clássico, demonstrativo, está presente em apenas uma resposta.

\section{Os exemplos de respostas e suas análises}

A seguir, apresentamos seis exemplos de respostas diversas dos estudantes a essa questão. Os três primeiros exemplos são aqueles que apresentaram linguagem que mais se aproximou do padrão do texto científico escolar. Assim, devido à identificação, nestas respostas, de uma maior articulação entre os eventos, consideramos o uso adequado de verbos de relação e um uso mais frequente de referentes abstratos de modo adequado à explicação proposta, na forma narrativa ou demonstrativa. Os demais exemplos apresentam graus diversos de respostas, com padrões que identificamos como mais próximos à linguagem cotidiana.

Primeiro exemplo: linguagem científica / texto explicativo narrativizado

Com a combustão e a respiração dos seres vivos há liberação de $\mathrm{CO}_{2}$ na atmosfera. Com a fotossintese as plantas absorvem o $\mathrm{CO}_{2}$ e formam a glicose. Quando os animais comem, o carbono passa a fazer parte deles e volta para a atmosfera através da respiração. Quando os seres vivos morrem os compostos de carbono se decompõem e viram combustiveis. Esses combustiveis são usados para faz̧er combustões e assim liberam $\mathrm{CO}_{2}$ na atmosfera. Assim, isso acontece tudo de novo, formando um ciclo. [Guilherme]

Consideramos que a ideia de ciclo está presente, como fio condutor do texto, conectando os eventos narrados. Identificamos, nessa resposta, a presença da narrativa com uma boa articulação dos acontecimentos, criando uma ação completa com uso de verbos e relação que compõem início/meio/fim utilizando os constituintes da figura apresentada. O estudante utiliza vários referentes abstratos - tais como $\mathrm{CO}_{2}$,glicose, carbono, compostos de carbono e 
ciclo - importantes na construção da história científica que se configura no contexto do ciclo do carbono. Algumas expressões utilizadas pelo estudante já são mencionadas na figura, como: combustão, respiração, fotossíntese, compostos de carbono e combustíveis. Merece, entretanto, destacar a atribuição adequada de relações causais entre esses processos nominalizados, o que é feito mediante verbos de relação. Nas frases - "Com a combustão e a respiração dos seres vivos há liberação de $\mathrm{CO}_{2}$ na atmosfera" e "Com a fotossíntese as plantas absorvem o $\mathrm{CO}_{2} \mathrm{e}$ formam a glicose" - verificamos o uso de nominalizações e de verbos como elementos de ligação entre processos (respiração e liberação de gás carbônico; fotossíntese e formação de glicose), características dos textos científicos. Em seu texto, com 82 palavras, o estudante utiliza a ideia de transformação nos verbos de relação "formam" e "viram”. Este último verbo, a nosso ver, evoca a ideia de transmutação.

Segundo exemplo: linguagem científica / texto científico demonstrativo

Este ciclo mostra que as moléculas em que há carbono não se criam nem se perdem, modificam-se. Nele o carbono dos alimentos são expirados e liberados da combustão, depois são utilizados pela fotossintese de plantas... Por isso podemos considerar que até um átomo de carbono que fez.parte de um dinossauro possa fazer parte de nós. [Gustavo]

Esse texto, mais curto e sintético do que o anterior (55 palavras), também apresenta evidências de apropriação e uso de linguagem científica. Os termos e ideias são abstratos, com atributos específicos desligados da experiência cotidiana e bem articulados em uma explicação que, ao contrário da anterior, não se limita a narrar uma cadeia linear de acontecimentos. Ao contrário, vemos aqui elementos de uma explicação genuína, que se inicia com a evocação de um princípio abstrato - a conservação do constituinte carbono. Em seguida, o estudante evoca processos como fotossíntese, respiração (não explícita no texto, mas talvez evocada ao falar do carbono sendo 'expirado') e combustão, para demonstrar e concluir (com uso do conectivo lógico 'por isso') que um átomo carbono, que fez parte de um dinossauro, poderia, hoje, constituir nosso próprio corpo. Esta é uma característica marcante dos textos científicos escolares que apresentam generalizações, explicam partes e, finalmente, concluem apresentando novos contextos. Além do uso de conectivos lógicos, observamos, também, o emprego de referentes específicos abstratos, como molécula e átomo, além do referente carbono. O texto apresenta uma incorreção conceitual, ao atribuir a conservação às 'moléculas em que há carbono', e não aos átomos de carbono. Esse texto evidencia, portanto, um conceito em formação, ainda incompleto e, potencialmente, fonte de erros e lacunas, mas com um potencial heurístico que inaugura um olhar diferenciado para o mundo em que vivemos. Indica, ainda, uma capacidade de manejar ideias abstratas por meio de raciocínio lógico-dedutivo, incomum nessa idade e período de escolarização.

Terceiro exemplo: linguagem científica / texto explicativo narrativizado

Do gás carbônico existente no ar, as plantas o utilizam para a fotossintese. A planta libera $\mathrm{O}_{2}$ que é usado na respiração bumana que volta para o ar. A planta passa 


\begin{abstract}
para seres bumanos o carbono através da alimentação e os animais, como respiram e comem plantas, possuem carbono assim passando para os seres humanos quando é comido. Nas cidades também bá liberação do carbono através de duas maneiras: Combustão dos automóveis e respiração bumana. Assim o carbono volta para o ar, que é utilizado pelas plantas... [Norma]
\end{abstract}

Assim como os dois primeiros textos, consideramos, nessa resposta, a predominância da linguagem científica; e, assim como o primeiro, a presença da explicação narrativizada. Identificamos o uso e importância atribuída aos referentes abstratos - gás carbônico, $\mathrm{O}_{2}$, carbono, compostos -, articulados com outros referentes mais próximos às experiências cotidianas - plantas, seres humanos, ar e combustíveis. Ocorre, ainda, o uso dos processos nominalizados - respiração, fotossíntese e combustão - que evidenciam uma aproximação da linguagem científica. Nota-se, entretanto, menor articulação de ideias do que os textos anteriores. O texto apresenta erros conceituais que podem ser interpretados de duas maneiras. A primeira interpretação é de que a origem de tais erros estaria na indiferenciação entre a substância (gás carbônico) e um de seus constituintes (o átomo de carbono). A outra interpretação é a de que a aluna complica-se ao produzir um texto com alta densidade léxica e encadeamento de ideias. Ao passar de um referente a outro, nas relações que vai estabelecendo sequencialmente, ela não utiliza adequadamente os pronomes, resultando em frases que ficam com sujeito indefinido. Por exemplo, na frase "A planta libera $\mathrm{O}_{2}$ que é usado na respiração humana que volta para o ar", não sabemos o que a aluna diz voltar para o ar: seria o oxigênio, o gás carbônico (mencionado anteriormente) ou o carbono (evocado no título da figura)?

Admitindo a hipótese de erros conceituais, consideramos a possibilidade de a ideia de transformação ser dada, para a estudante, como passagem do carbono, como na frase: "A planta passa para seres humanos o carbono através da alimentação e os animais, como respiram e comem plantas, possuem carbono assim passando para os seres humanos quando é comido". Entretanto, como o texto é lacunar, é possível admitir que o modo de dizer da aluna não explicita as transformações que a transferência de carbono, de uma parte a outra do sistema, deveria evocar.

Para os outros tipos de respostas, apresentamos, como exemplo, o uso da linguagem cotidiana com sequência textual explicativa, em que predominam, ora a narrativa, ora a descrição.

Quarto exemplo - linguagem cotidiana/ texto narrativo

$\mathrm{O} \mathrm{CO}_{2}$ encontrado nas plantas que são alimentos a outros seres que por respiração solta um pouco de $\mathrm{CO}_{2}$ para o ar e quando morrem viram combustiveis usados pelos seres bumanos e pela combustão são jogados no ar. [Rafael]

Identificamos, nesse texto, de 38 palavras, o uso predominante da linguagem cotidiana: quase todos os referentes são ligados a experiências cotidianas (plantas, alimentos, seres vivos, combustíveis e seres humanos); os verbos designam ações concretas desses seres ou materiais (são encontrados, morrem, viram, são usados, jogados); há poucas nominalizações (respiração, combustão) e referentes abstratos $\left(\mathrm{CO}_{2}\right)$. 
Nota-se, ainda, a fraca relação entre os acontecimentos narrados, o que diminui o potencial explicativo do texto. A ideia de transformação aparece como transmutação e a ideia de ciclo como passagem, sem transformações, o que caracteriza o carbono e o $\mathrm{CO}_{2}$ como constituintes indiferenciados. Entretanto, assim como o texto anterior, parte desses erros pode ser atribuída às dificuldades do estudante em produzir um texto, escrito com tantas e tão complexas relações, em um todo coerente. Se decompormos o texto do estudante, isolamos frases relativamente consistentes, mas com fraca coesão entre si: (1) $\mathrm{O} \mathrm{CO}_{2}$ é encontrado nas plantas; (2) [as plantas] são alimentos a outros seres [vivos]; (3) [os seres vivos], por respiração, soltam um pouco de $\mathrm{CO}_{2}$ para o ar; (4) quando morrem, [os seres vivos] viram combustíveis; (5) [os combustíveis] são usados pelos seres humanos; (6) pela combustão, [o $\mathrm{CO}_{2}$ ] são jogados no ar. Além dos conectivos, na última frase, não fica claro o que é lançado ao ar pela combustão: se os combustíveis ou o $\mathrm{CO}_{2}$ evocado no início do texto.

Quinto exemplo - linguagem cotidiana/ texto descritivo

Que primeiro passa pelo processo de combustão e vira gás carbônico, vira fotossintese, vai para as plantas vira comida, os animais comem e vai para as indústrias. [Pedro]

Esta resposta exemplifica o uso da linguagem cotidiana em que os elementos que compõem o texto não são narrados, antes, descritos a partir da figura, como que apontando para cada um deles. Os recursos linguísticos são ainda mais limitados do que no exemplo anterior, e a linguagem aproxima-se mais da linguagem oral do que da linguagem escrita, sem os recursos linguísticos que permitem, ao texto escrito, uma enunciação mais distanciada do contexto da comunicação face a face.

Encontramos o uso de referentes abstratos - gás carbônico e carbono - e referentes empíricos - plantas, comida e indústrias -, mas não há evidências de familiaridade com os primeiros. O estudante não diferencia processos, como fotossíntese, de substâncias ou coisas, como gás carbônico e plantas. A ideia de transformação é associada à ideia de transmutação com o uso do verbo vira. O uso da expressão "primeiro" e as relações em pares caracterizam a descrição da figura. A ideia de ciclo aparece apenas como passagem do constituinte gás carbônico de um sistema para o outro, e não há diferenciação entre o carbono e o gás carbônico. $\mathrm{O}$ texto é lacunar e o uso dos verbos "val" e "vira" escondem o constituinte do qual a matéria é formada. O uso dos pronomes e conectivos é inadequado e, como resultado, não conseguimos identificar o que "vai para as indústrias" e o que "vira fotossíntese", ou o que "vira comida".

Sexto exemplo - linguagem cotidiana/ texto explicativo com mescla de narração e descrição

Da combustão vai para o gás carbônico e vai para a fotossintese que vai para a árvore que é o composto de carbono nas plantas depois a vaca come e depois ela far. cocô e cai na planta e vai pra a respiração. [Samuel]

Na resposta do Samuel, encontramos o uso da linguagem cotidiana, com predominância do texto narrativo com forte presença da descrição dos constituintes da figura. O estudante 
estabelece uma cadeia de relações temporais - que vai; depois - com fraca articulação entre os acontecimentos. Ocorre o uso de referentes abstratos - gás carbônico e composto de carbono -, mas predominam os referentes empíricos - árvore, plantas, vaca e cocô. Os processos nominalizados - combustão, fotossíntese e respiração - estão presentes, sem compor as metáforas gramaticais e sem uma diferenciação entre processos (fotossíntese) e substâncias $\left(\mathrm{CO}_{2}\right)$ ou objetos (árvore). A ideia de transformação está associada à de transmutação por meio do uso do verbo "ir". Toda a resposta é acompanhada por erros conceituais, como, por exemplo, o uso indiferenciado de carbono e gás carbônico.

O Quadro 2 indica a frequência relativa de erros conceituais identificados nesta questão do pós-teste. Nele, podemos identificar: a alta frequência da indiferenciação entre o elemento carbono e o gás carbônico, a identificação do ciclo como passagem (sem transformação), e a noção de transformação como transmutação, ou seja, sem referência a grandezas ou entidades que se conservam no processo. Parte desses erros conceituais, como vimos, pode ser atribuída à complexidade da questão e dos elementos que compunham o diagrama apresentado no enunciado, assim como às dificuldades de uso, por parte dos estudantes, de textos explicativos com alta densidade léxica e grande número de relações envolvidas. Em contextos mais simples, em outros momentos da sequência de ensino, esses erros conceituais tiveram menor frequência.

Quadro 2. Frequência dos erros conceituais nas respostas à questão 1 do pós-teste

\begin{tabular}{|l|c|}
\hline \multicolumn{1}{|c|}{ Erros conceituais } & Frequência (total = 18 respondentes) \\
\hline Indiferenciação entre carbono e gás carbônico & $12(67 \%)$ \\
\hline Transformação como transmutação & $12(67 \%)$ \\
\hline Ciclo como passagem (sem transformação) & $11(61 \%)$ \\
\hline Gases da atmosfera são transformados pelas plantas em oxigênio & $3(17 \%)$ \\
\hline
\end{tabular}

Fonte: Elaborado pelos autores.

\section{Os textos dos estudantes como evidências do processo de formação de conceitos}

Ao examinar o problema da formação de conceitos, Vigotsky $(2001,2003)$ sugere transformações qualitativas no uso da palavra que explicam as transformações na forma de pensar na infância e adolescência. $O$ autor descreve tal evolução em três grandes fases: o pensamento sincrético, o pensamento por complexos e o pensamento por conceitos. No segundo estágio, o pensamento por complexos, as relações estabelecidas começam a superar as impressões subjetivas, demonstrando certa coerência e objetividade, mas as ligações entre os objetos ainda são concretas e factuais. Em todos os estágios mencionados, encontram-se formas de pensamento que conduzem, de acordo com Vigotsky: à formação de vínculos, ao estabelecimento de relações entre diferentes impressões concretas, à unificação e à generalização de objetos particulares, ao ordenamento e à sistematização de toda a experiência da criança. $\mathrm{O}$ autor considera que, no pensamento por complexo, os vínculos passam de subjetivos a objetivos, e que tais vínculos efetivamente existem entre os objetos. Em relação aos níveis anteriores (pensamento sincrético), 
trata-se de um progresso no modo de pensar no qual ocorre a unificação de objetos homogêneos em grupos comuns, de acordo com leis estabelecidas por vínculos objetivos. Apesar de apresentar características de coerência e objetividade superiores ao pensamento sincrético, ainda se difere do pensamento conceitual.

Segundo Vigotsky (2001), o complexo baseia-se em vínculos factuais, que se revelam na experiência imediata que se expressa no vínculo de objetos a grupos, levando em conta a semelhança física entre eles. Comparando o pensamento conceitual do pensamento por complexo, se poderia dizer que, enquanto no primeiro se reflete um vínculo essencial e uniforme e uma relação entre os objetos, no segundo, ocorre um vínculo concreto, factual e fortuito.

Em boa parte dos textos apresentados, os estudantes parecem se valer de complexos, e não de conceitos verdadeiros (VIGOTSKY, 2001) ao responderem a questão proposta. Para Vigotsky, a necessidade de uma referencialidade concreta é uma característica associada ao pensamento por complexos. Nos textos apresentados, os estudantes apoiam-se em substâncias conhecidas - gás carbônico, glicose - ou coisas - plantas, indústrias, atmosfera, combustíveis para compor generalizações. Ao mesmo tempo, utilizam referentes abstratos - átomo, molécula, elemento - e estabelecem vínculos parciais, por estarem fora do seu contexto prático. Como vimos nos últimos exemplos, o uso desses referentes em si não garante a apropriação dos conceitos. Como alerta Vigotsky, mesmo os três estudantes que, em suas respostas a essa questão, apresentaram sequências textuais próximas da linguagem científica, usam as palavras de modo adequado, mas podem apresentar operações mentais diferentes daquelas que são necessárias no uso do conceito científico.

Apesar disso, pensamos que os conceitos científicos estão se constituindo nesse processo e há progressos nos modos de falar e pensar dos estudantes. Os dados aqui apresentados indicam a complexidade do processo de formação de conceitos e a necessidade de estabelecermos metas de longo prazo, com recursividade no currículo da Educação Básica, para apropriação dos mesmos pelos estudantes.

Destacamos, ainda, a diversidade do desempenho dos estudantes na tarefa, e concluímos que ela pode ser valiosa para permitir o desenvolvimento de formas científicas de falar e pensar sobre o mundo nas salas de aula de ciências.

\section{Considerações finais}

Driver et al. (1994) apresentam uma visão de como os vários fatores da experiência pessoal, da linguagem e da socialização são inter-relacionados no processo de aprendizagem das ciências em sala de aula. Para os autores, o conhecimento científico é, ao mesmo tempo, simbólico por natureza e socialmente negociado. Mesmo em domínios considerados simples pelos educadores, por exemplo, em conceitos introdutórios, entre eles o de elemento químico, os conceitos usados para descrever e modelar as estruturas conceituais não se desenvolvem naturalmente ou de maneira óbvia. No contexto científico, essas construções fizeram parte de grandes esforços intelectuais, o que indica a impossibilidade de serem essas ideias científicas descobertas pelos estudantes por meio de sua investigação empírica. Os autores concluem que aprender ciências envolve não somente uma iniciação nas ideias e práticas da comunidade científica como, também, uma construção de sentidos dessas mesmas ideias e práticas em nível 
individual. Nesse contexto, ressaltam a importância do papel do professor como mediador entre o conhecimento científico e os estudantes, ajudando-os a dar sentidos aos significados atribuídos pela ciência.

Ao contrário da perspectiva piagetiana, Mortimer (2000) afirma que os indivíduos podem apresentar esquemas conceituais plurais apropriados a contextos sociais específicos, denominados perfis conceituais. Na perspectiva sociointeracionista, de acordo com Vigotsky (2001, 2003), o entendimento e o conhecimento científico são construídos quando os indivíduos engajam-se socialmente em conversações e atividades sobre problemas e tarefas comuns, em um processo dialógico. A aquisição desses modos de falar e pensar sobre o mundo não implicaria a substituição ou a submissão dos conceitos cotidianos por/aos conceitos científicos, mas a tomada de consciência de situações para as quais os conceitos científicos mostram-se necessários e adequados.

Nessa perspectiva, Mortimer (2000) conclui que o desafio estaria, portanto, em ajudar os estudantes a se apropriarem dos modelos da ciência, reconhecendo os seus domínios de aplicabilidade e o modo de usá-los. Para Driver et al. (1994), uma maneira importante de introduzir os estudantes em uma comunidade de conhecimentos é por meio do discurso no contexto de tarefas relevantes.

Os resultados encontrados fazem eco a outros estudos que investigam a linguagem utilizada por estudantes em textos escritos no contexto do ensino de ciências, e que apresentam transições entre linguagem científica e cotidiana (MORTIMER; CHAGAS, ALVARENGA, 1998; MORTIMER; VIEIRA; ARAÚJO, 2010), bem como das dificuldades de integração entre elementos que fazem parte do mundo vivido de objetos e fenômenos para o mundo concebido, dos conceitos e modelos científicos (MORTIMER, 1998).

Ao elaborarmos a questão no pós-teste, esperávamos que os estudantes, ao explicarem o ciclo do carbono na questão 1, utilizando o diagrama como suporte, utilizassem, em seu texto, os conceitos estudados na sequência didática que antecede ao teste, como elemento químico, substância e transformação. Mas deparamo-nos com um grande número de respostas que descrevem a figura utilizando os seus constituintes e alguns processos muito presentes no ensino de ciências, que são: a fotossíntese, a respiração e a combustão. O conceito de elemento químico, a nosso ver, não foi utilizado explicitamente nas respostas porque ainda não está consolidado no repertório dos estudantes. A maioria deles utilizou o gás carbônico como substância que contém o carbono sem, no entanto, explicitar o carbono como seu constituinte, considerando carbono e gás carbônico como se fossem a mesma entidade.

Talvez uma razão para as dificuldades encontradas pelos estudantes na tarefa esteja na complexidade da questão e, sobretudo, na dificuldade de leitura do diagrama apresentado. Estudos realizados por Roth, Pozzer-Ardenghi e Han (2005) indicam a complexidade das operações envolvidas na leitura do que os autores denominam inscrições em camadas. Os autores adotam a perspectiva de Latour (2000), segundo o qual as inscrições são dispositivos semióticos largamente empregados para sustentar e consolidar explicações em ciências. Várias dessas representações contêm múltiplos elementos, com posições diversas em um continuum entre o mundo vivido (de objetos e fenômenos) e o mundo concebido (de conceitos e modelos). Segundo os autores, a leitura dessas inscrições envolve uma complexidade de operações por parte dos estudantes. No caso da figura do enunciado da questão proposta, os estudantes devem compreender os sentidos das setas e nomes que conectam figuras familiares e outras que 
representam conceitos abstratos (carbono, compostos de carbono, representações de moléculas de dióxido de carbono etc.).

Outra razão está na dificuldade dos alunos em produzirem textos escritos com uma linguagem científica coesa e coerente. Em estudos amparados pelas ideias vigotskyanas, deparamo-nos com a possibilidade da discrepância entre a formação do conceito e a sua definição verbal. Para Vigotsky (2001), a existência de um conceito e a consciência desse conceito não coincidem quanto ao momento do seu surgimento, tampouco quanto ao seu funcionamento. $\mathrm{O}$ adolescente pode formar o conceito e empregá-lo em situação concreta, mas, ao ser demandada a sua definição verbal, esta se mostra restrita em comparação à aplicação. Encontramos, então, a situação em que o adolescente aplica a palavra como conceito e define-a como complexo, o que caracteriza a forma de pensamento nessa fase de transição. Outra dificuldade que, de acordo com Vigotsky, só é superada ao término da idade de transição, consiste na transferência do significado do conceito elaborado para novas situações concretas.

Já na escrita, encontramos diferenças que indicam a possibilidade de um aumento no grau de dificuldade em relação à definição verbal. Na escrita, o tom de voz e o conhecimento sobre o assunto são excluídos, e o adolescente deve utilizar mais palavras e com maior clareza. Para Vigotsky, a escrita é a forma de fala mais elaborada. Torna-se necessário o rascunho, chamado, por Vigotsky, de fala interior. Para esse autor, tanto a definição verbal quanto a escrita não são uma simples tradução da fala interior, mas uma transformação da estrutura predicativa e idiomática em sistematização articulada e inteligível para os outros. Identificamos momentos exemplares dessas formulações teóricas na análise das dinâmicas discursivas estabelecidas na sala de aula pesquisada e nas produções escritas dos estudantes nas avaliações escolares.

Tais ideias encontram ressonância na obra de Bakhtin (2003), que elabora uma distinção entre gêneros de discurso primários e secundários. Os gêneros primários são mais simples e dão-se nas condições da comunicação discursiva imediata da vida cotidiana. Já os gêneros secundários "surgem nas condições de um convívio cultural mais complexo e relativamente muito desenvolvido e organizado (predominantemente escrito)" (BAKHTIN, 2003, p. 263), ligados às atividades científicas, artísticas, políticas e outras. Durante o processo de sua formação, esses gêneros secundários absorvem e transmutam os gêneros primários (simples) e os alteram profundamente.

Em alguns dos textos, aliado à questão do uso e apropriação da linguagem científica, se coloca, aos estudantes, um desafio mais geral: o domínio da estrutura da língua escrita (uso de pronomes, pontuação e coesão textual, entre outros aspectos). Portanto, consideramos que professores de ciências devem dedicar especial atenção não apenas ao letramento científico, mas, também, ao letramento dos estudantes, em geral, tarefa de todos os educadores.

\section{Referências}

BAKHTIN, M. Estética da criação verbal. São Paulo: Martins Fontes, 2003.

BRONCKART, J. P. Atividade de linguagem, textos e discursos: por um interacionismo sócio-discursivo. São Paulo: EDUC, 1999.

DRIVER, R. et al. Constructing scientific knowledge in the classroom. Educational Researcher, Thousand Oaks, v. 23, n. 7, p. 5-12, 1994. 
Silva, N. S.; Aguiar Junior, O. G.

FONTANA, R. C. Mediação pedagógica na sala de aula. Campinas: Autores Associados, 2000.

HALLIDAY, M. A. K.; MARTIN, J. R. Writing science: literacy and discursive power. Pittsburgh: University of Pittsburgh Press, 1993.

LATOUR, B. Ciência em ação: como seguir cientistas e engenheiros sociedade afora. São Paulo: Ed. da UNESP, 2000.

LEMKE, J. L. Talking science: language, learning and values. Norwood: Ablex Publishing, 1990.

LIMA, M. E. C.; AGUIAR JR., O.; DE CARO, C. M. A formação de conceitos científicos: reflexões a partir da produção de livros didáticos. Ciência \& Educação, Bauru, v. 17, n. 4, p. 855-871, 2011.

MORTIMER, E. F. Linguagem e formação de conceitos no ensino de ciências. Belo Horizonte: Editora UFMG, 2000.

Sobre chamas e cristais: a linguagem cotidiana, a linguagem científica e o ensino de ciências.

In: CHASSOT, A.; OLIVEIRA, R. J. Ciência, ética e cultura na educação. São Leopoldo:

UNISINOS, 1998. p. 99-118.

MORTIMER, E. F.; CHAGAS, A. N.; ALVARENGA, V. T. Linguagem científica versus linguagem comum nas respostas escritas de vestibulandos. Investigações em Ensino de Ciências, Porto Alegre, v. 3, n. 1, p. 7-19, 1998.

MORTIMER, E. F.; SCOTT, P. Meaning making in secondary science classrooms. Maidenhead: Open University Press, 2003.

MORTIMER, E. F.; VIEIRA, A. C. F. R.; ARAÚJO, A. O. Letramento científico em aulas de química. In: MARINHO, M.; CARVALHO, G. T. (Org.). Cultura escrita e letramento. Belo Horizonte: Editora UFMG, 2010. p. 234-253.

OGBORN, J. et al. Explaining science in the classroom. Buckingham: Open University Press, 1996.

ROTH, W. M.; POZZER-ARDENGHI, L.; HAN, J. Y. The work of reading layered inscriptions. In:__ Critical graphicacy: understanding visual representation practices in school science. Dordrecht: Springer, 2005. p. 159-186.

SILVA, N. S. Modos de uso e o processo de apropriação do conceito de elemento químico por estudantes do ensino fundamental. 2009. 231 f. Tese (Doutorado) - Faculdade de Educação, Universidade Federal de Minas Gerais, Belo Horizonte, 2009.

SUTTON, C. R. Words, science and learning. Buckingham: Open University Press, 1992.

VIGOTSKY, L. S. A construção do pensamento e da linguagem. São Paulo: Martins Fontes, 2001.

A formação social da mente. 6. ed. São Paulo: Martins Fontes, 2003.

WELLS, G. Learning to use scientific concepts. Santa Cruz: University of California, 2008.

WERTSCH, J. V. Mind as action. New York: Oxford University Press, 1998.

Voices of the mind: a sociocultural approach to mediated action. Hertfordshire: Harvester Wheatsheaf, 1991.

Artigo recebido em 10/09/13. Aceito em 16/07/14. 